\title{
1 Evidence for major contributions of unintentionally- 2 produced PCBs in the air of China: implications for the 3 national source inventory
}

4

5 Shizhen Zhao ${ }^{1}$, Kevin C. Jones ${ }^{2}$, Jun $\mathrm{Li}^{1}$, Andrew J. Sweetman ${ }^{2}$, Xin Liu ${ }^{1}$, Yue Xu ${ }^{3}$, Yan Wang ${ }^{4}$, Tian

$6 \quad \mathrm{Lin}^{5}$, Shuduan $\mathrm{Mao}^{6}$, Kechang $\mathrm{Li}^{1}$, Jiao Tang ${ }^{1}$, Gan Zhang ${ }^{* 1}$

$8{ }^{1}$ State Key Laboratory of Organic Geochemistry, Guangzhou Institute of Geochemistry, Chinese

9 Academy of Sciences, Guangzhou, 510640, China

$10{ }^{2}$ Lancaster Environment Centre, Lancaster University, Lancaster, LA1 4YQ, UK

$11{ }^{3}$ State Key Laboratory of Environmental Geochemistry, Institute of Geochemistry, Chinese

12 Academy of Sciences, Guiyang 550002, China

$13{ }^{4}$ Key Laboratory of Industrial Ecology and Environmental Engineering (MOE), School of

14 Environmental Science and Technology, Dalian University of Technology, Dalian, 116024, China

$15{ }^{5}$ College of Marine Ecology and Environment, Shanghai Ocean University, Shanghai, 201306,

16 China

$17{ }^{6}$ College of Environmental and Resource Sciences, Zhejiang University, Hangzhou 310058, China

$18 *$ Corresponding author:

19 Gan Zhang

20 Tel: +86 (0) 85290805

21 Email: zhanggan@gig.ac.cn 


\section{Abstract}

24 Polychlorinated biphenyls (PCBs) were not widely manufactured or used in China before they

25 became the subject of international bans on production. Recent work has shown they have

26 reached China associated with imported wastes, and that there are considerable unintentional

27 sources of PCBs that have only recently been identified. As such, it was hypothesised that the

28 source inventory and profile of PCBs may be different or unique in China, compared to countries

29 where they were widely used and which have been widely studied. For the first time in this study

30 we therefore undertook a complete analysis of 209 PCB congeners and assessed the contribution

31 of unintentionally-produced PCBs (UP-PCBs) in the atmosphere of China, using polyurethane foam

32 passive air samplers (PUF-PAS) deployed across a wide range of Chinese locations. $\sum_{209}$ PCBs

33 ranged from 9 to $6856 \mathrm{pg} / \mathrm{m}^{3}$ (median: $95 \mathrm{pg} / \mathrm{m}^{3}$ ) during three deployments in 2016-2017. PCB 11

34 was one of the most detected congeners, contributing $33 \pm 19 \%$ to $\sum_{209} P C B s$. The main sources to

35 airborne PCBs in China were estimated and ranked as pigment/painting (34\%), metallurgical

36 industry/combustion (31\%), e-waste (23\%) and petrochemical/plastic industry (6\%). For typical

37 Aroclor-PCBs, e-waste source dominated (>50\%). Results from our study indicate that UP-PCBs

38 have become the controlling source in the atmosphere of China and an effective control strategy

39 is urgently needed to mitigate emissions from multiple industrial sources. 


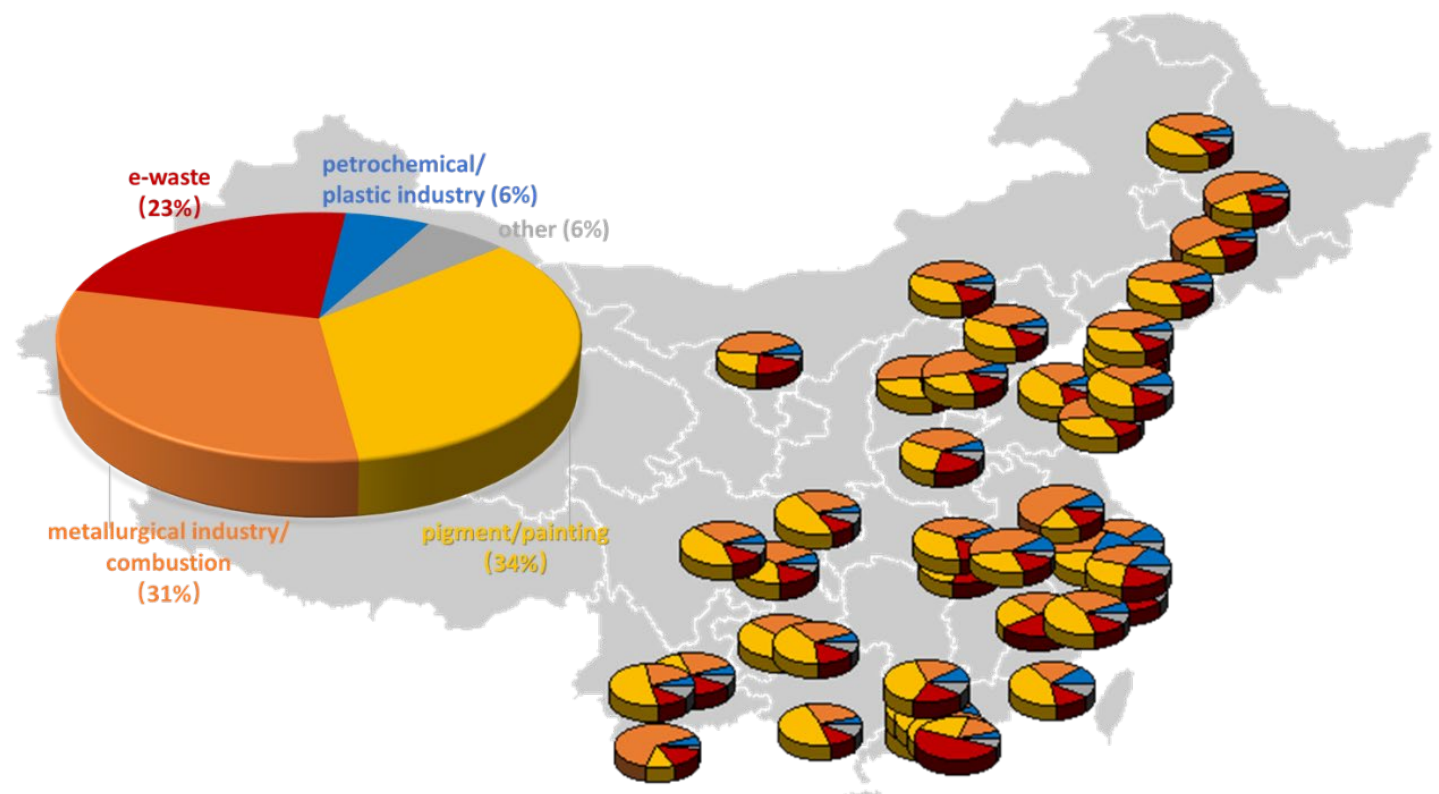

42 Keywords

43 Source apportionment; Passive air samplers; Polychlorinated biphenyls; unintentionally-produced $44 \quad$ PCBs (UP-PCBs) 
47 Polychlorinated biphenyls (PCBs) are one of twelve legacy persistent organic pollutants (POPs) 48 initially regulated by the Stockholm Convention, ${ }^{1}$ because they are toxic and stable in the 49 environment, may undergo long-range atmospheric transport (LRAT), and bioaccumulate via the 50 food chain, representing a potential threat to environmental and human health. ${ }^{2,3}$ PCBs were 51 originally deliberately produced between 1930 s - 1970s as complex mixtures with a theoretical 52 possible 209 different congeners. ${ }^{4,5}$ They were given the trade name Aroclor in the US, thus we 53 used "Aroclor-PCBs" here to denote PCB congeners with historical production. During this time, 54 an estimated $\sim 1.4$ million tonnes of PCBs were deliberately manufactured. China was not a main 55 PCB producer, only accounting for $\sim 1 \%$ of the total global production, with Chinese production 56 finishing in $1974 .{ }^{6}$ Nonetheless, these compounds are still of great concern in China and are

57 frequently detected in the Chinese environment. ${ }^{7,8}$ Much of this attention has arisen because of 58 the presence of PCBs in imported e-wastes. ${ }^{9,}{ }^{10}$ Indeed, it was reported that airborne PCBs in China 59 increased from 2004 to $2008^{11}$ at a time when the trend in other parts of the world was the 60 opposite..$^{12-14}$

61 PCBs emitted into the atmosphere can originate from both intentionally produced (IP-PCBs) and

62 unintentionally-produced (UP-PCBs) sources. The latter are by-products of industrial processes. ${ }^{15}$

63 Attention on UP-PCBs is relatively recent. Given: (i) the very small production and use of Aroclor-

64 PCBs in China; (ii) the huge industrial and chemical manufacturing base of China, (iii) China's

65 commitment to the Stockholm Convention, which requires it to publish a national source 66 inventory and assess the effectiveness of source abatement measures, a significant question is

67 therefore 'what is the contribution of UP-PCBs in the Chinese atmosphere?' This question is of 68 key interest for policy makers, since it will affect their perception of the need to reduce or 
69 eliminate primary emissions and the effectiveness of emission reduction strategies. We have

70 demonstrated that the UP-PCBs will probably become a main contributor from 2035 by modeling

71 current and future emission sources for China. ${ }^{9}$ These projections are mainly linked to widespread

72 industrial thermal processes for producing steel, cement and iron ore, etc. ${ }^{15,16}$ However, this was

73 just a pilot study, based on seven indicator Arolcor- PCBs, and needs to be tested by field

74 observations.

75 Understanding atmospheric emission sources largely relies on accurate determination of the

76 occurrence and spatial distribution of PCB ambient air concentrations. Previous studies have

77 mainly focused on a selection of congeners which was dominated by IP-PCBs. ${ }^{12,}{ }^{17,}$, ${ }^{18}$ However,

78 several monitoring studies have recently pointed out that that UP-PCBs, such as PCB $47 / 48 / 75^{7}$

79 and PCB $11^{19-21}$ contribute significantly to the present level of PCBs. Hence, monitoring merely

80 based on a limited number of PCB congeners could bias the estimated contribution from various

81 PCB sources.

82 In this study, we therefore conducted a national atmospheric PCB campaign from 2016 to 2017,

83 using polyurethane foam passive air samplers (PUF-PAS) to: 1). investigate occurrence, spatial

84 distribution and congener pattern of airborne PCBs in China; 2) estimate the relative contributions

85 of PCB sources to China's atmospheric burden of PCBs, by source apportionment; 3) discuss the

86 implications for source controls and policy. To the best of our knowledge, this is the first study to

87 draw comprehensive source profiles of PCBs on a national scale in China. 


\section{Methods}

89

\section{Sampling design}

We selected two types of sampling sites, source sites and non-sources sites. Sources sites were close to areas with various industrial activities, namely steel production, coking, petrochemical, dying, pigment, e-waste dismantling, etc. Samples from non-source sites presented the general PCBs profile in urban, rural and remote sites. The strategy behind site selection was to utilize measured emission profiles of source-sites as the fingerprint to decode the relative contribution of multiple sources to current airborne PCBs in China. PUF-PAS samplers integrate air over many weeks of deployment, and is a cost-effective method which can be used in multiple sites with no requirement for electricity. It has therefore been widely used in regional and global scale monitoring studies for PCBs and other POPs. ${ }^{11,18,22}$ The specification and photos of used PUF-PAS were described in Figure S1 and Table S10. The advantages of utilizing PUF-PAS to investigate various emission profiles are: 1) well-mixed and long-term deployed passive air samples are more representative than grab samples. The traditional grab samples of flue gas/ash just represent instant short-term emission patterns. It may only capture PCBs in the gas or particle phase and significantly differentiate among various thermal industrial processes, whilst PUF-PAS capture both air and particle phases. ${ }^{23}$ All PUF-PAS were deployed for 7-8 weeks near emission sites, representing a well-mixed and stable emission profile of a specific source; 2) most currently available emission profiling only has a limited number of congeners analyzed, mainly focused on the Aroclor-PCBs and dioxin like-PCBs (dl-PCBs). Emission profiles based on analysis of all 209 congeners can provide insight into the $\mathrm{PCB}$ emission pattern from a full range of industrial activities. 
110 All the site information and sampling periods are detailed in Table S1. In summary, PUF-PAS were

111 deployed at 62 sampling sites across China for three cycles in autumn and winter of 2016 and

112 summer of 2017 . The effective sampling rate was determined via calibrated model detailed

113 elsewhere. ${ }^{23}$ Prior to deployment, PUF-PAS were pre-cleaned and shipped to the sampling sites

114 with installation instructions for local operators to deploy. All samples were delivered back to the

115 lab and stored at $-20^{\circ} \mathrm{C}$ before analysis.

\section{Sample pretreatment and analysis}

117 The detailed methods for sample treatment and instrumental analysis are given in a previous 118 study. ${ }^{7}$ In short, each sampled PUF disk was spiked with ${ }^{13} \mathrm{C}_{12}$-labeled PCBs (PCB 11, 155 and 206)

119 as recovery standards and extracted in a Soxhlet apparatus for $24 \mathrm{~h}$ with hexane and acetone (1:1, $120 \mathrm{v} / \mathrm{v})$. The extracts were concentrated via rotary evaporator and solvent-exchanged into hexane 121 with reduced volume of $0.5-1 \mathrm{~mL}$. They were then purified by a multilayer acidified silica gel 122 column and concentrated into a vial under a gentle stream of nitrogen. ${ }^{13} \mathrm{C}_{12}$-labelled PCBs (PCB $12377,101,141,178)$ were added as internal standards before instrumental analysis. Samples were 124 analyzed on an Agilent 7890A/7000A GC-MS/MS with a CP-Sil 8 CB column $(50 \mathrm{~m} \times 0.25 \mathrm{~mm} \times$ $1250.12 \mu \mathrm{m}$ ) in a multiple reaction monitoring (MRM) mode for measuring all 209 PCB congeners.

126 The precursor and product ions are detailed in Table S2, and retention times are listed in Table S3.

127 Quality assurance and quality control (QA/QC)

128 QA/QC was conducted using field blanks, procedural blanks and surrogates spiked recoveries.

129 Most congeners were not detected in the field blanks and procedural blanks. The average 130 recovery rates of ${ }^{13} \mathrm{C}_{12}$ labelled 11,155 and 206 were $62 \pm 13 \%, 71 \pm 11 \%$ and $76 \pm 12 \%$, respectively.

131 The reported concentration data were corrected for blanks and surrogate recovery. The method 132 detection limits (MDLs) were assigned as the average values of field blanks plus 3 times their 
133 standard deviations. MDLs were calculated as three times of instrumental detection limits (IDLs)

134 if a congener was not detected in field and procedural blanks. IDLs were defined as the amounts

135 of analytes generating a signal-to-noise of 3:1 using the lowest standard concentration, assuming

136 a linear increase of response. The IDLs and MDLs of 209 PCB congeners were in ranges of $0.2-470$

137 pg and $0.002-16 \mathrm{pg} / \mathrm{m}^{3}$ presented in Table S4.

\section{Positive Matrix Factorization (PMF)}

139 The Positive Matrix Factorization (PMF) method is a model for solving a receptor-only, bilinear

140 unmixed model which assumes that a measured dataset conforms to a mass-balance of a number

141 of constant source profiles, contributing varied concentrations. Its advantages over PCA is the

142 uncertainty-weighting of each data point and matches the observation of the real-source

143 signature without requiring the dataset orthogonal to each other. ${ }^{24}$ Thus, it has been widely used

144 to identify possible sources of PCBs and many other POPs. ${ }^{24-26}$

145 The input data file consisted of receptor concentration (C) and uncertainty (U) matrixes. Measured

146 PCB concentrations were entered separately for each deployment at each site. PCB congeners

147 below the limit of detection in $>50 \%$ of samples were excluded from the PMF model. $U$ for each

148 variable was calculated using $C$ and the MDL as suggested. ${ }^{24}$ In order to determine the optimal

149 number of sources, the model was tested for 2-8 factors by running 20 times with a random seed

150 to determine the stability of $Q$ values, a parameter measuring the impact of data points with high

151 scaled residuals. To evaluate the degree of fitting of PCB congeners for estimating emission

152 profiles, the coefficient of determination $\left(R^{2}\right)$ measuring the goodness of fit between the

153 measured and modelled concentrations was used. Calculated $\mathrm{R}^{2}$ were all greater than 0.5 for all

154 the congeners. The initial matrix was composed of 121 samples $\times 93$ species and the results are 155 summarized in Table S5. 
157 Spatial variation of the factor scores, comparison of congener patterns with known sources (both

158 from a literature review and from observations in this study at source sites), and presence of the 159 non-Aroclor congeners were considered to identify the resolved factors. The cosine theta 160 similarity metric, a measure of similarities between two vectors, was used to match congeners 161 patterns. ${ }^{27} \quad$ Selected $\mathrm{PCB}$ profiles included unaltered Aroclor mixtures $162\left(1221,1232,1016,1242,1248,1254,1260,1262\right.$ and 1268), ${ }^{28,29} \# 1$ PCB $^{30}$ (a commercial product of 163 China), Kanechlor products (KC300, KC400, KC500, KC600) and emissions from incineration of 164 municipal solid waste $^{5,31}$ and cement kilns co-processing solid waste, ${ }^{32}$ wood and coal 165 combustion, ${ }^{33,}{ }^{34}$ electronic arc furnaces, ${ }^{16,}{ }^{31}$ water treatment plants ${ }^{35}$ and various types of 166 pigments. ${ }^{36,37}$ To consider the potential contributions of emissions of PCBs from production 167 banned in the past, profiles of volatilized Aroclor mixtures were also included and obtained by

168 multiplying the individual congener concentration by corresponding subcooled liquid vapor 169 pressure $(\mathrm{Pa})$ from measurements or estimated from regressions, if measurements were not 170 available. ${ }^{38}$

171 Results and Discussion

\section{PCB profiles in the air of China}

173 Measured PCB concentrations for all samples ( $n=167)$ are summarized in Table S6. In summary, $174 \sum_{209}$ PCBs broadly ranged from 9 to $6856 \mathrm{pg} / \mathrm{m}^{3}$ (median: $95 \mathrm{pg} / \mathrm{m}^{3}$ ) in varied sites as listed in Table 175 S1. $\Sigma_{7}$ indicator PCBs (i-PCBs) and $\Sigma_{12}$ dl-PCBs contributed on average $~ 5 \%$ and $\sim 1 \%$ to the total $176 \sum_{209}$ PCBs concentrations. Concentrations of $\sum_{7} \mathrm{i}-\mathrm{PCBs}$ were significantly positively related to the $177 \sum 209$ PCBs concentration as shown in Figure $S 2\left(R^{2}>0.99, p<0.001\right)$. Lower chlorinated (mono to tri-) 178 PCBs dominated the composition, contributing $>70 \%$ at all non-source sites. On average, di-CBs 
179 accounted for $\sim 40 \%$ to the $\sum_{209}$ PCBs, mainly due to the contribution of PCB 11 . Previous studies

180 have quantified fewer congeners and usually excluded mono-CBs and di-CBs, therefore drawing

181 a different conclusion that tri-CBs is the dominant homologue group in China. ${ }^{11,18}$

182 No statistical difference was observed for the seasonal variation for concentrations of $\sum_{209}$ PCBs

183 shown in Figure S3-a, b, c (Kruskal-Wallis $\mathrm{H}$ test, $\mathrm{p}=0.273$ ), although significant differences were 184 observed for mono-CBs $(P<0.05)$, which were much higher in winter $\left(47 \pm 63 \mathrm{pg} / \mathrm{m}^{3}\right)$, than autumn $185\left(22 \pm 26 \mathrm{pg} / \mathrm{m}^{3}\right)$ and summer $\left(17 \pm 22 \mathrm{pg} / \mathrm{m}^{3}\right)$. This exhibits the same seasonal trend as combustion186 related airborne pollutants, like PAHs, so it may indicate the contribution of combustion emissions 187 and domestic heating. ${ }^{39,} 40$ It has been demonstrated that combustion sources profiles were 188 largely dominated by the lower chlorinated congeners, including PCB 1, PCB 2 and PCB 3. ${ }^{41,42}$ 189 Meanwhile, mono-CBs are dominant in Aroclor 1221 and Aroclor 1232, accounting for up of 60\%, 190 which may also be a potential source via relevant recycling activities/combustion. In addition, 191 lower mixing atmospheric height may increase pollutant concentration in winter. ${ }^{39}$

192 Higher concentrations of PCBs were observed in developed and populated zones along the 193 Chinese east coast to the south coast, from the region of the Yangtze River Delta to the Pearl River 194 Delta (see Figure S3). These two regions share the main proportion ( $>50 \%$ ) of the historical PCBs 195 usage in China. ${ }^{43}$ They are also the regions where e-waste recycling sites have been intensively 196 located. ${ }^{8,44}$ As expected, the highest concentration was observed at an e-waste dismantling site 197 located in an industrial park of Taizhou, where concentrations averaged at $6460 \pm 460 \mathrm{pg} / \mathrm{m}^{3}$. 198 Another e-waste site in Qingyuan also had high PCB concentrations, but nearly an order of 199 magnitude lower than in Taizhou $\left(835 \pm 224 \mathrm{pg} / \mathrm{m}^{3}\right)$. This difference may have been caused by 200 varied dismantling techniques of e-waste recycling activities. ${ }^{45}$ 
202 A significant reduction was observed when comparing the concentrations of the 18 commonly 203 measured PCB congeners with other passive air sampling studies conducted in China in $2004^{18}$, $2042005^{46}$ and $2008^{11}$ (see Table S7), with similar composition dominant by tri-PCBs. Our 205 measurements were on a similar level $\left(\sim 60 \mathrm{pg} / \mathrm{m}^{3}\right)$ compared to those measured in 2004 and 2005, 206 but an order of magnitude lower than the observation in 2008. An increasing trend was also 207 observed in sedimentary records from Eastern China since 1990s, which closely follow the growth 208 of PCBs emission from industrial thermal process and e-waste sources. ${ }^{17}$ Chinese government 209 released the standard for pollution control on PCBs in contaminated wastes (GB 13015-91) in 1991 210 and updated a new version (GB 13015-2017) in 2017. But there is no relevant regulation and rule 211 on controlling PCBs emission from unintentional sources so far.

212 The comparison of PCB levels with other regions is summarized in Table S8. PCB concentrations 213 in Chinese air are often found to be comparable with regions with intensive historical manufacture 214 and usage of PCBs, such as Japan, Korea and the USA. ${ }^{11,18,47}$ Levels are much higher than 215 observations in King George Island ${ }^{48}$ and the Group of Latin American and Caribbean (GRULAC) 216 countries. ${ }^{22}$ Several urban sites had high levels of PCBs, e.g. Zhengzhou City in winter $\left(1056 \mathrm{pg} / \mathrm{m}^{3}\right)$,

217 which is comparable to PCBs level in Chicago, ${ }^{47,49}$ London and Manchester. ${ }^{14}$

218 These observations are contradictory to the historically minor production and usage of PCBs in 219 China, which only accounts for around $1 \%$ to the global production. One possible reason is the 220 large importation of e-waste, which is illegal and difficult to track. ${ }^{10}$ Improper dismantling and 221 recycling activities give rise to elevated levels around these sites. ${ }^{45}$ Another factor possibly 222 contribution to the higher level is the inappropriate management and disposal of 
223 decommissioned capacitors. ${ }^{18,}{ }^{50}$ Finally, unintentionally-produced PCBs from multiple industrial

224 processes may also contribute to the current levels of PCBs in Chinese ambient air. 9, $^{15}$

\section{Spatial transect}

226 PCB levels measured at various sampling sites were ranked as follows: e-waste sites (3010 \pm 2076

$\left.227 \mathrm{pg} / \mathrm{m}^{3}\right)>>$ industrial sites $(152 \pm 103)>$ urban sites $\left(124 \pm 126 \mathrm{pg} / \mathrm{m}^{3}\right)>$ rural sites $\left(87 \pm 30 \mathrm{pg} / \mathrm{m}^{3}\right)>$

228 remote sites $\left(70 \pm 140 \mathrm{pg} / \mathrm{m}^{3}\right)$. In terms of $\sum_{209} \mathrm{PCB}$ concentrations, all types of sites had statistically

229 significant differences (Kruskal-Wallis $\mathrm{H}$ test, $\mathrm{p}<0.05$ ), except for the datasets between rural and

230 urban sites $(p=0.08)$. The decreasing gradient indicated the important contribution of PCBs from

231 e-waste and potential sources relate to multiple industrial activities. ${ }^{15}$ However, the decreasing

232 gradient was less pronounced than previously observed differences, which have ranged over 1-2

233 orders of magnitude. ${ }^{51,52}$ This may be due to the re-location of various industrial activities from

234 urban areas to semirural/rural areas, driven by the Chinese government ${ }^{53}$ and an implementation

235 gap of environmental policies in rural areas. ${ }^{54}$ Another possible reason may be less usage of PCBs

236 in urban areas of China, compared to some other countries, such as in building materials used in

237 the US, Norway and elsewhere. ${ }^{55}$

238 It is interesting to note that, penta and hexa-CBs contributed most ( $14 \%$ and $\sim 9 \%)$ in remote sites

239 as shown in Figure S3-d. Normally, low chlorinated PCBs with relatively high volatility are expected

240 to move to remote regions more efficiently, whereas higher chlorinated PCBs with lower volatility

241 tend to remain in the surface compartments within, or in the vicinity of, source regions. ${ }^{52}$ The

242 spatial distribution of PCB homologues in industrial, urban and rural area satisfied this expectation.

243 The sum contribution of penta- and hexa-CBs was ranked as remote sites $>$ e-waste sites >

244 industrial sites $>$ urban sites $>$ rural sites. The penta-CBs in remote sites were mainly contributed

245 by PCB 125 and PCB 111+117, which were detected in commercial products of KC 500 and KC 400, 
246 and the flue gas of incineration from incinerators in similar composition. ${ }^{5}$ Whilst, PCB 130 and PCB

247162 were the main contributors in hexa-CBs, occupying no or very limited portion in commercial

248 products. These congeners are not routinely measured in previous studies. However, their levels

249 and contributions were comparable to these in source sites, such as petrochemical and steel

250 industry. The reason of contrasting with typical congeners profiles dominated by tri-CBs is that

251 the measurement of the full set of 209 congeners here, highlighting the roles of penta- and hexa-

252 CBs, which were potentially ignored before. Though most remote sites were selected from the

253 network of national monitoring sites of background air, these sites were located and designed to

254 monitor standard air quality compositions, such as $\mathrm{PM}_{2.5}$ and $\mathrm{NO}_{x}$, not for POPs. The remote sites

255 greatly dominated by penta and hexa-CBs was mainly located in the developed and populated

256 regions in eastern and southern China, such as Cape D'Aguilar in Hongkong and Hengxi in Zhejiang

257 province, which were potentially affected by the local hidden stockpiles, potential illegal e-waste

258 dismantling and industrial sources relocated therein owing to the much strengthened air pollution

259 control policy in Chinese cities 


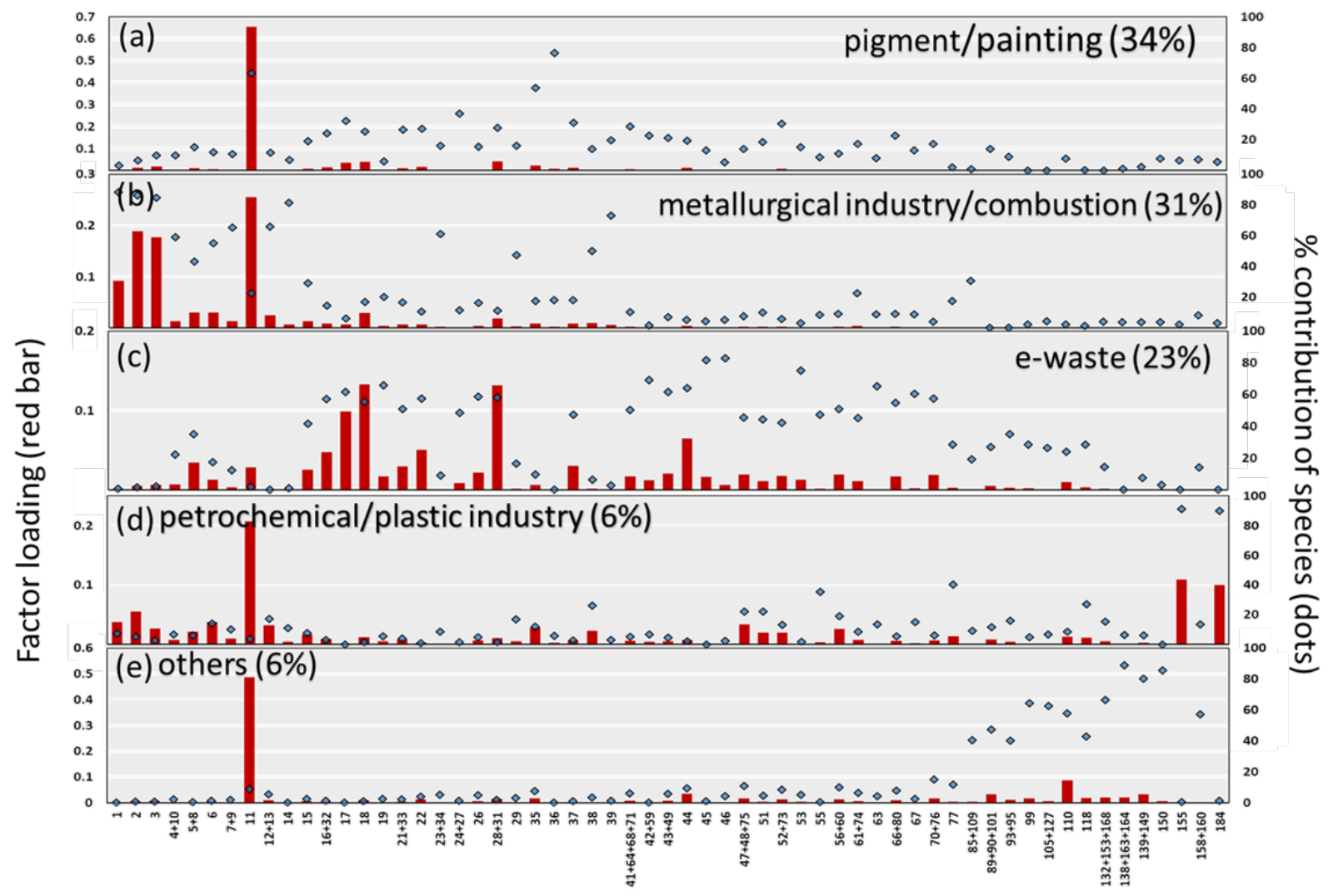

Figure 1. Source profiles gained from positive matrix factorization analysis of airborne PCBs (a-e). Bars represent factor loading and dots represent contribution (\%) of selected species of each 264 source factor.

265 Five source types were identified by PMF for airborne PCBs in China captured by PAS-PUF in this study and are presented in Figure 1. The first factor (Figure 1-a) was responsible for $34 \%$ of the PCB masses. with a high loading of PCB 11 (a non-Aroclor congener), contributing $63 \%$ of the sum, which is similar to previous studies conducted around the Great Lakes. ${ }^{56}$ PCB 11 is the dominant congener present in azo-pigments, as discussed previously. ${ }^{42}$ This estimated concentration profile

270 (Figure 1-a) had the highest similarity with samples from dying and pigment sources ( $\cos \theta=0.96-$

271 0.99). Therefore, the first factor should represent volatilization from paints/pigments and/or

272 wastewater receiving paints/pigments industries. However, all factors (Figure 1-a, b, d, e) except

273 for e-waste sources (Figure 1-c) gained a high factor loading from PCB 11, with relatively low 
274 contribution to total congeners (2-22\%), indicating universal and potentially overlooked sources

275 of PCB 11 requiring further investigation.

276 The second factor (Figure 1-b) could explain 31\% of the total PCB masses with a high loading and 277 contribution of lower-chlorinated PCBs (PCB 1,2,3, 85-88\% of species sum). This estimated 278 emission profile has a strong similarity $(\cos \theta=0.93-0.99)$ to the measured profile in source 279 regions of the steel, coking and motor industries. Previous direct measurements from waste 280 incineration flue gas showed a similar congener pattern, which was dominated by low chlorinated 281 congeners. ${ }^{41}$ As a result, the second factor was considered as the combined source of metallurgic 282 industry and combustion.

283 The third factor (Figure 1-c) was responsible for $23 \%$ of the total PCB masses, with a high factor 284 loading of Aroclor-PCBs, mainly including PCB 28/31 (58\%), 17 (62\%), 18 (55\%). Other typical 285 Aroclor congeners, such as PCB 37, 44, 49 and 66 all greatly contributed to the total species sum, 286 ranging from $42-82 \%$. This congener pattern is consistent with the commercial products, 287 dominated by tetra-CBs, similar to the composition of Aroclor 1248 (the US), KC400 (Japan) and 288 \#1 PCB (China). However, its similarity with these original and volatized Aroclor-type commercial 289 products was relatively low ( $\cos \theta=0.05-0.38)$, possibly because the pattern could be altered 290 during the transport and recycling of commercial products. Close similarity was observed with 291 measurements of e-waste sources sampled in Qingyuan and Taizhou ( $\cos \theta=0.78-0.89$ ). As a 292 result, it is concluded that this factor is the characteristic emission from e-waste sources.

293 The fourth factor (Figure 1-d), only explained 6\% of the total PCB masses, was also characterized 294 relatively high factor loadings of PCB 11, 155, 184. All these congeners are non-Aroclor PCBs, with 295 no link to intentional production and historical usage of PCBs. PCB 155 and 184 together 296 contributed $90 \%$ of the sum of PCB species. This factor is similar to samples from petrochemical 
297 industries in Shanghai and Dongying City in Shandong Province ( $\cos \theta=0.86-0.93$ ) and source 298 samples from plastic manufacture in Yuyao city, Zhejiang Province ( $\cos \theta=0.81-0.92)$. Yuyao is the 299 largest center of manufacturing and producing plastic products in China. ${ }^{57}$ This factor was 300 therefore regarded as the combined source from petrochemical and plastic industries. PCB 155 301 and 184 could be considered as potential markers of these two sources.

302 Lastly, the fifth factor (Figure 1-e), also contributed $6 \%$ to the total PCB masses. However, its 303 congener pattern did not match well with source profiles from this study or the literature. This 304 factor also had a high loading of PCB 11, and of several Aroclor PCBs, like PCB 101, 110, 118, 138 305 and $139 / 149$, contributing $47-88 \%$ to the species sum. These congeners are often dominant in 306 Aroclor 1260 and equivalent commercial products. Shang et al. also observed PCB 101, 138 and 307153 in yellow pigment samples in China. ${ }^{58}$ Thus, we speculate that this factor could be from 308 combined sources of pigment and Aroclor 1260 or its equivalents. However, labeled as "other" in 309 Figure 1-e, this needs to be investigated further and will not be discussed in detail here. 


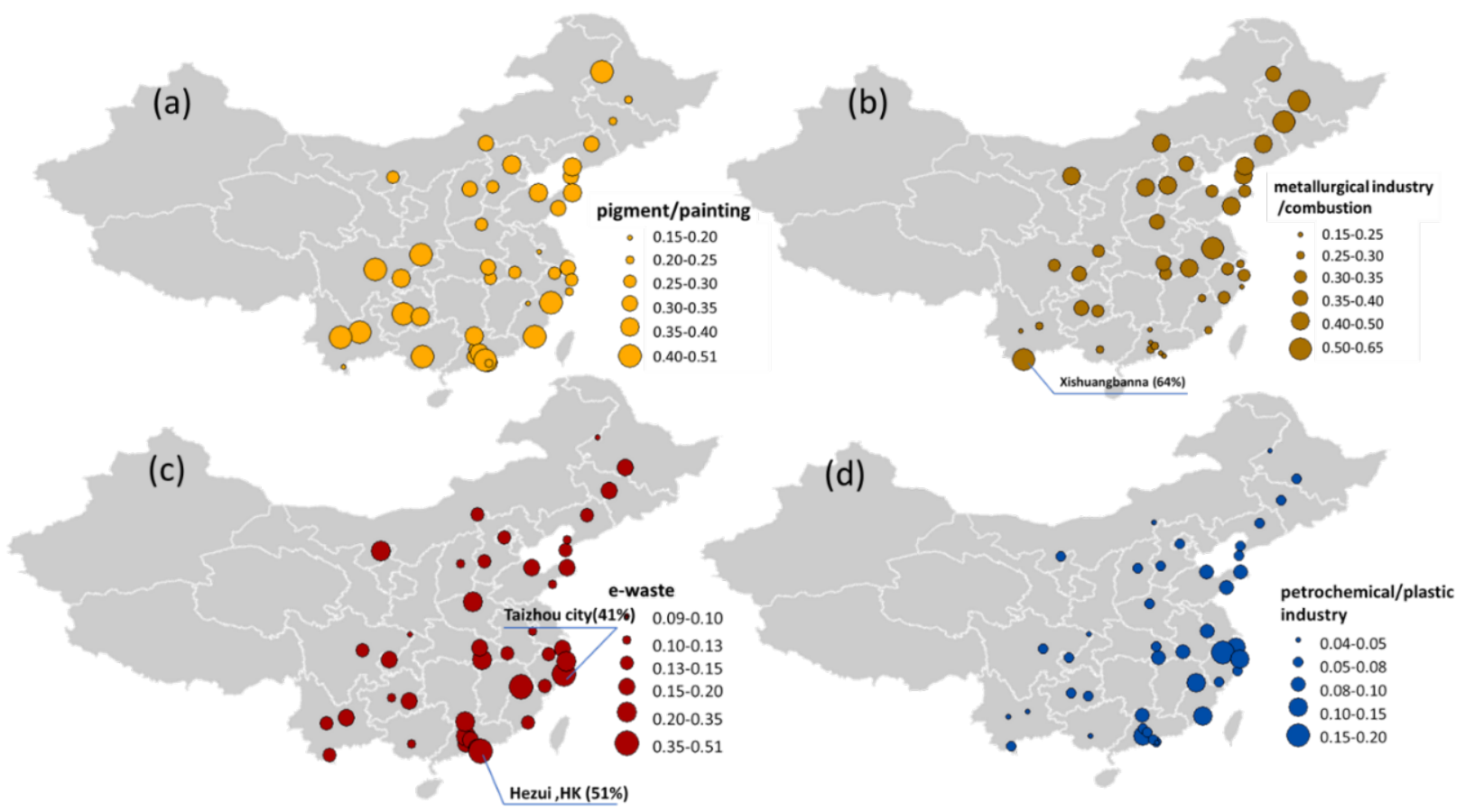

Figure 2. Normalized contributions of the PMF source factors for the autumn deployment (Oct-

313 Dec, 2016).

314 Normalized contributions of the PMF source factors for the samples collected in autumn of 2016

315 are presented in Figure 2. The sources from volatilized pigment/paintings (Figure 2-a) were

316 relatively well-mixed across China, with a contribution ranging from $15-51 \%$. Southern China is

317 more strongly affected than the northern parts, which might be following a similar trend as PCB

$31811 .^{59}$ Warmer temperatures increase the painted/pigmented surfaces. In addition, the pigment-

319 related source also showed a seasonal variation with a significantly increased contribution in

320 summer $(45 \pm 6 \%)$ than that in autumn $(31 \pm 8 \%)$ and winter $(30 \pm 8 \%)$.

321 In contrast, the metallurgical industry and combustion sources were calculated to contribute

322 larger proportions in northern China than in the south, as presented in Figure 2-b. This spatial

323 pattern is consistent with the distribution of the metallurgical industries and heating supply in

324 China. Higher contributions of this source type were observed in typical industrial cities like 
325 Changchun, Shijiazhuang and Shenyang. However, the highest contribution from this source (64\%)

326 occurred in Xishuangbanna of Yunnan Province, which is probably related to biomass burning.

327 Based on the backward trajectory analysis (Figure S6-b), these sites mainly received air masses

328 originating from Laos (61\%) and Myanmar (39\%), regions with intensive opening burning of

329 forests, crop residues, grassland and savanna. ${ }^{60}$ With higher contributions in winter than in

330 summer ( $36 \pm 11 \%$ vs. $22 \pm 3 \%)$, this source also showed opposite seasonal variation compared with

331 the pigment/paint sources. Its temporal trend is very similar to that for PAHs which are known to

332 be widely emitted from combustion sources. ${ }^{61}$

333

334 Figure 3. Relative contribution of identified source to the urban, rural and remote sites in three 335 deployments.

336 E-waste sources (Figure 2-c) responsible for $10-51 \%$ of total PCB concentrations at multiple 337 sampling sites (annual average $22 \pm 8 \%$ ), showed no seasonal difference. It is noteworthy that 338 several remote sites received much higher contributions from the e-waste related sources than 339 urban and rural sites as shown in Figure 3. For example, the Cape D'Aguilar site in Hong Kong was 340 estimated to have the highest loading of e-waste sources (51\%), even higher than the urban site 341 (41\%) of Taizhou City, around $20 \mathrm{~km}$ away from an e-waste site. One potential explanation for this 
342 could be the relocation of e-waste dismantling activities from suburban and/or rural areas to more

343 remote sites, to try to avoid legal sanctions. Another possible reason may be that this site received

344 pollutants from long-range atmospheric transport. According to the backward trajectory analysis

345 (Figure S5-a), this sampling site mainly received air from eastern China (49\%) and Taiwan (52\%)

346 during sampling in autumn 2016. This signal may be polluted by e-waste activities and/or release

347 from storage of historical products. Half of the total amount of PCBs used in China were in the

348 eastern regions of the country. ${ }^{43}$

349 The petrochemical industry/ plastic source was estimated to contribute $4-17 \%$ of the total PCBs.

350 The highest contribution occurred in sites near the source regions of the plastic and petrochemical

351 industries, such as the urban site in Hangzhou (17\%), remote sites in Ningbo city, eastern China

$352(14 \%)$, close to Yuyao city, the 'home' of China's plastics industry. On another hand, eastern and

353 northern sites with major petrochemical industrial activities were in Donying city of Shandong

354 Province and Shanghai. All these sites shared relatively high contributions (12-14\%) from the 355 sources of petrochemical industry. This spatial trend also matched well with the geographical 356 distribution of petrochemical industry in China, which is most intensive in the eastern China.

\section{UP-PCBs contribution to Aroclor-PCBs}

358 The contribution of various sources to the typical Aroclor-PCB signal was estimated by taking six 359 indicator PCB congeners as the key signature, namely PCB 28, 52, 101,118,138 and 153. PCB 180 360 was not included, due to low $\mathrm{R}^{2}$ calculated by PMF. The main contributor to this profile was e361 waste (51\%), followed by the pigment/painting sources (10\%). This is consistent with our previous 362 modelling result, indicating that e-waste still plays an important role to the current PCBs loadings 363 in the air of China. ${ }^{9}$ Meanwhile, a substance-specific emission pattern was observed, as shown in 364 Figure S7. For instance, PCB 28 was originated mainly from the e-waste (58\%) and 
365 pigment/painting sources (28\%), whilst PCB 153 was dominated by other mixed sources (66\%),

366 the petrochemical/plastic industry signal (15\%) and e-waste (15\%). Since PCB 28 is the dominant

367 congener amongst the six indicator PCBs, targeted control of the e-waste source will greatly

368 mitigate the PCB emissions. Therefore, effective control measures should be developed for

369 individual substance. Further studies to confirm the "other mixed sources" are also needed,

370 though they contributed only a minor amount for total PCBs emission.

\section{Comments on pigment-relevant congeners}

372 PCB 11 is the most important pigment-relevant congener. ${ }^{19}$ Its spatial distribution and seasonal

373 variation are shown in Figure S4-S5. It is one of the most frequently detected congeners, with $99 \%$

374 detection frequency. It contributed most $(33 \pm 19 \%)$ among all the congeners to the $\sum_{209} P C B s$. This

375 is much higher than the $\sim 15 \%$ in Chicago in $2007,{ }^{21}$ but lower than the $\sim 79 \%$ reported in 376 Antarctica. ${ }^{48}$ The concentration of PCB-11 averaged $35 \pm 33 \mathrm{pg} / \mathrm{m}^{3}\left(<\mathrm{MDL}-249 \mathrm{pg} / \mathrm{m}^{3}\right)$ and was

377 higher in summer, due to the relatively high volatility of di-CBs and suggested volatilization from

378 surfaces to which it had been applied..$^{62}$ The ranking of PCB 11 levels in the various categories of 379 sampling sites is in order of industry $>$ rural $>$ urban $>$ remote, indicating it is positively related to 380 human activities. Our PCB 11 concentrations were comparable to those in the urban air of the 381 US $^{21,59}$ and higher than most studies in other regions as shown in Table S9. An increasing trend 382 was observed from the first observation in 2012 of Beijing. ${ }^{63}$ Other PCB associated with pigments 383 include PCB 35 and PCB 77 together with PCB 11 in azo-type pigment, and PCB 209, 206, 207 and 384208 in phthalocyanine-type pigment. ${ }^{42} 100 \%$ and 57\% detection rates were observed for PCB 35 385 and 77, whilst PCB 209, PCB 208, PCB 207 and PCB 206 were detected less frequently (46\%, 4\%, $38624 \%, 17 \%)$ and at lower concentrations. 
387 This study is the first to comprehensively assess the occurrence and fate of PCB 11 in the air of 388 China. It has been demonstrated to be mainly emitted from azo-type pigments. ${ }^{42}$ China has 389 become the largest manufacturer of organic pigments in the world. ${ }^{58}$ According to the report of 390 the China Dyestuffs Industry Association (CDIA), ${ }^{64}$ the azo-type pigment and phthalocyanine 391 pigment contributed $59 \%$ and $24 \%$ to the total organic pigment/paints production in China, which 392 would release approximately 130 and 0.1 tonnes of PCB 11 and PCB 209, respectively. This was 393 just a crude emission estimate based on the formulation measurement of pigment produced by 394 companies from China, ${ }^{58}$ UK, Japan, the Netherlands and so on. ${ }^{36,37}$ Chinese products contain a 395 wider range of PCB 11 and other congeners, potentially leading to even higher PCBs emission. ${ }^{58}$ 396 Therefore, further studies to confirm sources and develop their emission inventories are urgently 397 needed.

\section{Limitations and implications}

399 There is still insufficient characterization of sources, particularly unknown sources, which limits

400 the present study. Data gap of PCB emission sources is inevitable, such as the source profile of 401 sewage treatment plants and indoor air. Our preliminary strategy is to take advantage of the 402 existing literature to close these gaps. However, reports of comparative patterns for sources are 403 limited, which makes pattern matching for fingerprints challenging. This may be the reason why 404 the fifth source factor could not be fully-confirmed by existing emission profiles. With PCB 11 and 405 other congeners volatilizing from the surface of pigments and paints, indoor air will be an 406 important source contributing to PCB emissions and could raise health issues from indoor 407 exposures. The occurrence of PCBs and their metabolites in indoor air and exposure risk to the 408 general population are not well-studied so far in China. 
409 Passive air sampler monitoring studies often meets several common challenges. ${ }^{65}$ Firstly, since

410 most of PUF-PAS were installed by volunteers, uncertainty could exist in the placement of samples.

411 Several abnormally high concentrations may be potentially caused by improper placement near

412 ventilation systems with potential indoor sources. Secondly, PUF-PAS captured both particle and

413 atmospheric phase simultaneously. ${ }^{23}$ Whilst, most studies used active sampler to obtain emission

414 profiles, mostly focused on the particulate phase and/or merely considered the gas phase with

415 selected congeners. ${ }^{5,31,66}$ This could cause big challenge for congener profile matching between

416 source and non-source PCBs profile. Hence, we considered that the emission profile consistently

417 gained by PUF-PAS would have higher similarity than that from the literature data.

418 More than four decades have passed since the international ban on PCB manufacture and use,

419 but China still receives on-going emissions of PCBs from multiple sources, particularly from

420 unintentional sources (UP-PCBs). Our findings suggest that the UP-PCBs have become the

421 dominant source across China, accounting for $\sim 65 \%$ to the total emissions. Volatilization from

422 pigment/painting sources and metallurgical industry/combustion are shown here to be the most

423 important sources nationally. This raises new issues for regulators and policy makers to develop

424 relevant UP-PCBs emission inventories and establish additional effective strategies to control

425 unintentionally-produced sources. Meanwhile, the contribution of e-waste as a PCB source

426 cannot be neglected, particularly for Aroclor-PCBs, like indicator PCBs (>50\%). It is challenging to

427 differentiate this source as either intentional or unintentional, due to unknown mechanisms of

428 PCB origin. If it comes from the de novo synthesis of e-waste dismantling activity, this source is an

429 unintentional source. Previous studies evaluating the mass fluxes of organic contaminants

430 released during incomplete incineration concluded that incinerators could be sinks or sources,

431 depending on the waste feed and combustion temperature. ${ }^{66,67}$ It is important to understand the 
432 mechanism of PCB emission during e-waste dismantling activities. Such studies are scarce, but

433 would greatly enhance the effectiveness of source control.

434 The transect profile of PCBs among urban, rural and remotes sites has been shifted under the 435 impact of human activities, as demonstrated in our study. We used to utilize the remote sites as 436 the background sites to investigate the baseline environmental level of target compounds. 437 However, in several selected remote sites in this study, which was assumed to be far-away from 438 human activities, unexpected high concentrations of PCBs were observed, like in Cape D'Aguilar 439 in Hongkong and Hengxi in Zhejiang province, both working as the regional background sties to 440 offer the baseline information of air quality in China. But they are originally designed to monitor 441 regulated air pollutants instead of POPs. As a result, using their PCBs level may cause potential 442 bias and it's worthwhile to review the applicability of these national monitoring sites to monitor 443 background level of POPs-like chemicals, which has been banned for long time and may be well444 mixed on a national scale. On another hand, the relocation of intensive thermal industrial sources 445 from urban region to suburban, rural regions and even "remote" regions, as a result of more 446 strengthened government policy, ${ }^{53}$ leads to some potential hot spots of UP-PCBs in the rural and 447 remote area. More attention should be paid to investigate the impact of industrial relocation on 448 the health risk of local population.

\section{Supporting Information}

450 Description of sampler and sampling campaign; methods on instrumental analysis; PMF outputs;

451 summary of PCBs concentration; comparison with other studies; spatial-temporal plots of PCB 11;

452 backward trajectory analysis; source contribution for varied sites and for selected Aroclor-PCBs. 
454 This work was supported by National Key R\&D Program of China (2017YFC0212004), Local

455 Innovative Scientific Research Team Project of Guangdong "Pearl River Talents Plan"

456 (2017BT01Z134), and China Postdoctoral Science Foundation (2017M622814, 2018T110898).

457 Thanks to Mr. Li Jiangtao on helping sample pretreatment. We also greatly thank all the local

458 volunteers helping setting up and retrieving passive air samplers.

\section{References}

460 1. UNEP The Stockholm Convention on Persistent Organic Pollutants; United Nations 461 Environmental Programme: 2001.

462 2. Jones, K. C.; de Voogt, P., Persistent organic pollutants (POPs): state of the science. 463 Environmental Pollution 1999, 100, (1-3), 209-221.

464 3. Desforges, J.-P.; Hall, A.; McConnell, B.; Rosing-Asvid, A.; Barber, J. L.; Brownlow, A.; De 465 Guise, S.; Eulaers, I.; Jepson, P. D.; Letcher, R. J.; Levin, M.; Ross, P. S.; Samarra, F.; Víkingson, G.; 466 Sonne, C.; Dietz, R., Predicting global killer whale population collapse from PCB pollution. Science 467 2018, 361, (6409), 1373.

468 4. Breivik, K.; Sweetman, A.; Pacyna, J. M.; Jones, K. C., Towards a global historical emission 469 inventory for selected PCB congeners - a mass balance approach: 2. Emissions. Science of The 470 Total Environment 2002, 290, (1), 199-224.

$471 \quad$ 5. Kim, K. S.; Hirai, Y.; Kato, M.; Urano, K.; Masunaga, S., Detailed PCB congener patterns in 472 incinerator flue gas and commercial PCB formulations (Kanechlor). Chemosphere 2004, 55, (4), 473 539-553.

$474 \quad$ 6. $\quad$ Xu, Y.; Tian, C.; Wang, X.; Ma, J.; Tang, J.; Chen, Y.; Li, J.; Zhang, G., An improved inventory 475 of polychlorinated biphenyls in China: A case study on PCB-153. Atmospheric Environment 2018, $476 \quad 183,40-48$.

$477 \quad 7 . \quad$ Mao, S.; Zhang, G.; Zhao, S.; Li, J.; Liu, X.; Cheng, Z.; Zhong, G.; Malik, R. N.; Liu, X., High 478 Abundance of Unintentionally Produced Tetrachlorobiphenyls (PCB47/48/75, 51, and 68) in the 479 Atmosphere at a Regional Background Site in East China. Environmental Science \& Technology $480 \quad 2019,53,(7), 3464-3470$.

$481 \quad$ 8. Qiao, L.; Zheng, X. B.; Zheng, J.; Chen, S. J.; Zhong, C. Q.; Chen, J. H.; Yang, Z. Y.; Mai, B. X., 482 Legacy and Currently Used Organic Contaminants in Human Hair and Hand Wipes of Female E483 Waste Dismantling Workers and Workplace Dust in South China. Environmental Science \& 484 Technology 2019, 53, (5), 2820-2829. 
9. Zhao, S.; Breivik, K.; Liu, G.; Zheng, M.; Jones, K. C.; Sweetman, A. J., Long-Term Temporal Trends of Polychlorinated Biphenyls and Their Controlling Sources in China. Environmental Science \& Technology 2017, 51, (5), 2838-2845.

10. Breivik, K.; Armitage, J. M.; Wania, F.; Jones, K. C., Tracking the Global Generation and Exports of e-Waste. Do Existing Estimates Add up? Environmental Science \& Technology 2014, 48, (15), 8735-8743.

11. Hogarh, J. N.; Seike, N.; Kobara, Y.; Habib, A.; Nam, J.-J.; Lee, J.-S.; Li, Q.; Liu, X.; Li, J.; Zhang, G.; Masunaga, S., Passive air monitoring of PCBs and PCNs across East Asia: A comprehensive congener evaluation for source characterization. Chemosphere 2012, 86, (7), 718-726.

12. Hung, H.; Katsoyiannis, A. A.; Brorstrom-Lunden, E.; Olafsdottir, K.; Aas, W.; Breivik, K.; Bohlin-Nizzetto, P.; Sigurdsson, A.; Hakola, H.; Bossi, R.; Skov, H.; Sverko, E.; Barresi, E.; Fellin, P.; Wilson, S., Temporal trends of Persistent Organic Pollutants (POPs) in arctic air: 20 years of monitoring under the Arctic Monitoring and Assessment Programme (AMAP). Environmental Pollution 2016, 217, 52-61.

13. Sun, P.; Basu, I.; Blanchard, P.; Brice, K. A.; Hites, R. A., Temporal and Spatial Trends of Atmospheric Polychlorinated Biphenyl Concentrations near the Great Lakes. Environmental Science \& Technology 2007, 41, (4), 1131-1136.

14. Graf, C.; Katsoyiannis, A.; Jones, K. C.; Sweetman, A. J., The TOMPs ambient air monitoring network - Continuous data on UK air quality for over 20 years. Environmental Pollution 2016, 217, 42-51.

15. Liu, G.; Zheng, M.; Jiang, X.; Jin, R.; Zhao, Y.; Zhan, J., Insights into the emission reductions of multiple unintentional persistent organic pollutants from industrial activities. Chemosphere 2016, 144, 420-424.

16. Odabasi, M.; Bayram, A.; Elbir, T.; Seyfioglu, R.; Dumanoglu, Y.; Bozlaker, A.; Demircioglu, H.; Altiok, H.; Yatkin, S.; Cetin, B., Electric Arc Furnaces for Steel-Making: Hot Spots for Persistent Organic Pollutants. Environmental Science \& Technology 2009, 43, (14), 5205-5211.

17. Wu, Z.; Lin, T.; Li, A.; Zhou, S.; He, H.; Guo, J.; Hu, L.; Li, Y.; Guo, Z., Sedimentary records of polychlorinated biphenyls in the East China Marginal Seas and Great Lakes: Significance of recent rise of emissions in China and environmental implications. Environmental Pollution 2019, 254, 112972.

18. Jaward, F. M.; Zhang, G.; Nam, J. J.; Sweetman, A. J.; Obbard, J. P.; Kobara, Y.; Jones, K. C., Passive Air Sampling of Polychlorinated Biphenyls, Organochlorine Compounds, and Polybrominated Diphenyl Ethers Across Asia. Environmental Science \& Technology 2005, 39, (22), 8638-8645.

19. Vorkamp, K., An overlooked environmental issue? A review of the inadvertent formation of PCB-11 and other PCB congeners and their occurrence in consumer products and in the environment. Science of the Total Environment 2016, 541, 1463-1476. 
20. Bartlett, P. W.; Isaksson, E.; Hermanson, M. H., 'New' unintentionally produced PCBs in 523 the Arctic. Emerging Contaminants 2019, 5, 9-14.

524 21. Hu, D.; Martinez, A.; Hornbuckle, K. C., Discovery of Non-Aroclor PCB (3,3 '525 Dichlorobiphenyl) in Chicago Air. Environmental Science \& Technology 2008, 42, (21), 7873-7877.

526 22. Rauert, C.; Harner, T.; Schuster, J. K.; Eng, A.; Fillmann, G.; Castillo, L. E.; Fentanes, O.; 527 Ibarra, M. V.; Miglioranza, K. S. B.; Rivadeneira, I. M.; Pozo, K.; Zuluaga, B. H. A., Air monitoring of 528 new and legacy POPs in the Group of Latin America and Caribbean (GRULAC) region. 529 Environmental Pollution 2018, 243, 1252-1262.

530 23. Herkert, N. J.; Spak, S. N.; Smith, A.; Schuster, J. K.; Harner, T.; Martinez, A.; Hornbuckle, 531 K. C., Calibration and evaluation of PUF-PAS sampling rates across the Global Atmospheric Passive 532 Sampling (GAPS) network. Environ Sci-Proc Imp 2018, 20, (1), 210-219.

533 24. Aydin, Y. M.; Kara, M.; Dumanoglu, Y.; Odabasi, M.; Elbir, T., Source apportionment of 534 polycyclic aromatic hydrocarbons (PAHs) and polychlorinated biphenyls (PCBs) in ambient air of 535 an industrial region in Turkey. Atmospheric Environment 2014, 97, 271-285.

536 25. Praipipat, P.; Meng, Q.; Miskewitz, R. J.; Rodenburg, L. A., Source Apportionment of 537 Atmospheric Polychlorinated Biphenyls in New Jersey 1997-2011. Environmental Science \& 538 Technology 2017, 51, (3), 1195-1202.

$53926 . \quad$ Du, S.; Belton, T. J.; Rodenburg, L. A., Source apportionment of polychlorinated biphenyls 540 in the tidal Delaware River. Environmental Science \& Technology 2008, 42, (11), 4044-4051.

541 27. Rodenburg, L. A.; Du, S.; Xiao, B.; Fennell, D. E., Source apportionment of polychlorinated 542 biphenyls in the New York/New Jersey Harbor. Chemosphere 2011, 83, (6), 792-798.

543 28. Frame, G. M.; Cochran, J. W.; Bøwadt, S. S., Complete PCB congener distributions for 17 544 aroclor mixtures determined by 3 HRGC systems optimized for comprehensive, quantitative, 545 congener-specific analysis. Journal of High Resolution Chromatography 1996, 19, (12), 657-668.

546 29. Wyrzykowska, B.; Bochentin, I.; Hanari, N.; Orlikowska, A.; Falandysz, J.; Yuichi, H.; 547 Yamashita, N., Source determination of highly chlorinated biphenyl isomers in pine needles 548 Comparison to several PCB preparations. Environmental Pollution 2006, 143, (1), 46-59.

549 30. Huang, J.; Matsumura, T.; Yu, G.; Deng, S.; Yamauchi, M.; Yamazaki, N.; Weber, R., 550 Determination of PCBs, PCDDs and PCDFs in insulating oil samples from stored Chinese electrical 551 capacitors by HRGC/HRMS. Chemosphere 2011, 85, (2), 239-246.

$552 \quad$ 31. Liu, G.; Zheng, M.; Cai, M.; Nie, Z.; Zhang, B.; Liu, W.; Du, B.; Dong, S.; Hu, J.; Xiao, K., 553 Atmospheric emission of polychlorinated biphenyls from multiple industrial thermal processes. 554 Chemosphere 2013, 90, (9), 2453-2460.

$555 \quad 32 . \quad$ Jin, R.; Zhan, J.; Liu, G.; Zhao, Y.; Zheng, M.; Yang, L.; Wang, M., Profiles of polychlorinated 556 biphenyls (PCBs) in cement kilns co-processing solid waste. Chemosphere 2017, 174, 165-172. 
33. Lee, R. G. M.; Coleman, P.; Jones, J. L.; Jones, K. C.; Lohmann, R., Emission factors and importance of PCDD/Fs, PCBs, PCNs, PAHs and PM10 from the domestic burning of coal and wood in the UK. Environmental Science \& Technology 2005, 39, (6), 1436-1447.

34. Gullett, B. K.; Touati, A.; Hays, M. D., PCDD/F, PCB, HxCBz, PAH, and PM Emission Factors for Fireplace and Woodstove Combustion in the San Francisco Bay Region. Environmental Science \& Technology 2003, 37, (9), 1758-1765.

35. Yao, M.; Li, Z.; Zhang, X.; Lei, L., Polychlorinated Biphenyls in the Centralized Wastewater Treatment Plant in a Chemical Industry Zone: Source, Distribution, and Removal. Journal of Chemistry 2014, 2014, 10.

36. Anezaki, K.; Nakano, T., Concentration levels and congener profiles of polychlorinated biphenyls, pentachlorobenzene, and hexachlorobenzene in commercial pigments. Environmental Science and Pollution Research 2014, 21, (2), 998-1009.

37. Anezaki, K.; Kannan, N.; Nakano, T., Polychlorinated biphenyl contamination of paints containing polycyclic- and Naphthol AS-type pigments. Environmental Science and Pollution Research 2015, 22, (19), 14478-14488.

38. Schenker, U.; MacLeod, M.; Scheringer, M.; Hungerbühler, K., Improving Data Quality for Environmental Fate Models: A Least-Squares Adjustment Procedure for Harmonizing Physicochemical Properties of Organic Compounds. Environmental Science \& Technology 2005, 39, (21), 8434-8441.

39. Dumanoglu, Y.; Gaga, E. O.; Gungormus, E.; Sofuoglu, S. C.; Odabasi, M., Spatial and seasonal variations, sources, air-soil exchange, and carcinogenic risk assessment for PAHs and PCBs in air and soil of Kutahya, Turkey, the province of thermal power plants. Science of The Total Environment 2017, 580, 920-935.

40. Lohmann, R.; Northcott, G. L.; Jones, K. C., Assessing the Contribution of Diffuse Domestic Burning as a Source of PCDD/Fs, PCBs, and PAHs to the U.K. Atmosphere. Environmental Science \& Technology 2000, 34, (14), 2892-2899.

41. Jansson, S.; Lundin, L.; Grabic, R., Characterisation and fingerprinting of PCBs in flue gas and ash from waste incineration and in technical mixtures. Chemosphere 2011, 85, (3), 509-515.

42. Anezaki, K.; Nakano, T.; Kashiwagi, N., Estimation of Polychlorinated Biphenyl Sources in Industrial Port Sediments Using a Bayesian Semifactor Model Considering Unidentified Sources. Environmental Science \& Technology 2016, 50, (2), 765-771.

43. Cui, S.; Fu, Q.; Li, Y. F.; Li, T. X.; Liu, D.; Dong, W. C.; Wang, M.; Li, K. Y., Spatial-temporal variations, possible sources and soil-air exchange of polychlorinated biphenyls in urban environments in China. Rsc Advances 2017, 7, (24), 14797-14804.

44. Zhang, K.; Schnoor, J. L.; Zeng, E. Y., E-Waste Recycling: Where Does It Go from Here? Environmental Science \& Technology 2012, 46, (20), 10861-10867. 
45. Liu, R.; Ma, S.; Li, G.; Yu, Y.; An, T., Comparing pollution patterns and human exposure to atmospheric PBDEs and PCBs emitted from different e-waste dismantling processes. Journal of Hazardous Materials 2019, 369, 142-149.

46. Zhang, Z.; Liu, L.; Li, Y.-F.; Wang, D.; Jia, H.; Harner, T.; Sverko, E.; Wan, X.; Xu, D.; Ren, N.; Ma, J.; Pozo, K., Analysis of Polychlorinated Biphenyls in Concurrently Sampled Chinese Air and Surface Soil. Environmental Science \& Technology 2008, 42, (17), 6514-6518.

47. Hu, D.; Lehmler, H.-J.; Martinez, A.; Wang, K.; Hornbuckle, K. C., Atmospheric PCB congeners across Chicago. Atmospheric Environment 2010, 44, (12), 1550-1557.

48. Wang, P.; Li, Y.; Zhang, Q.; Yang, Q.; Zhang, L.; Liu, F.; Fu, J.; Meng, W.; Wang, D.; Sun, H.; Zheng, S.; Hao, Y.; Liang, Y.; Jiang, G., Three-year monitoring of atmospheric PCBs and PBDEs at the Chinese Great Wall Station, West Antarctica: Levels, chiral signature, environmental behaviors and source implication. Atmospheric Environment 2017, 150, 407-416.

49. Persoon, C.; Peters, T. M.; Kumar, N.; Hornbuckle, K. C., Spatial Distribution of Airborne Polychlorinated Biphenyls in Cleveland, Ohio and Chicago, Illinois. Environmental Science \& Technology 2010, 44, (8), 2797-2802.

50. Weber, R.; Schlumpf, M.; Nakano, T.; Vijgen, J., The need for better management and control of POPs stockpiles. Environmental Science and Pollution Research 2015, 22, (19), 1438514390.

51. Melymuk, L.; Robson, M.; Helm, P. A.; Diamond, M. L., PCBs, PBDEs, and PAHs in Toronto air: Spatial and seasonal trends and implications for contaminant transport. Science of The Total Environment 2012, 429, 272-280.

52. Harner, T.; Shoeib, M.; Diamond, M.; Stern, G.; Rosenberg, B., Using Passive Air Samplers To Assess Urban-Rural Trends for Persistent Organic Pollutants. 1. Polychlorinated Biphenyls and Organochlorine Pesticides. Environmental Science \& Technology 2004, 38, (17), 4474-4483.

53. Wang, Y.; Liu, Y.; Li, Y.; Li, T., The spatio-temporal patterns of urban-rural development transformation in China since 1990. Habitat International 2016, 53, 178-187.

54. Wang, M.; Webber, M.; Finlayson, B.; Barnett, J., Rural industries and water pollution in China. Journal of Environmental Management 2008, 86, (4), 648-659.

55. Marek, R. F.; Thorne, P. S.; Herkert, N. J.; Awad, A. M.; Hornbuckle, K. C., Airborne PCBs and $\mathrm{OH}-\mathrm{PCBs}$ Inside and Outside Urban and Rural U.S. Schools. Environmental Science \& Technology 2017, 51, (14), 7853-7860.

56. Khairy, M.; Muir, D.; Teixeira, C.; Lohmann, R., Spatial Distribution, Air-Water Fugacity Ratios and Source Apportionment of Polychlorinated Biphenyls in the Lower Great Lakes Basin. Environmental Science \& Technology 2015, 49, (23), 13787-13797.

57. Sun, Z.; Perry, M., The role of trading cities in the development of chinese business cluster. International Business Research 2008, 1, (2), 69-81. 
58. Shang, H.; Li, Y.; Wang, T.; Wang, P.; Zhang, H.; Zhang, Q.; Jiang, G., The presence of polychlorinated biphenyls in yellow pigment products in China with emphasis on 3,3'dichlorobiphenyl (PCB 11). Chemosphere 2014, 98, 44-50.

59. Basu, I.; Arnold, K. A.; Venier, M.; Hites, R. A., Partial pressures of PCB-11 in air from several Great Lakes sites. Environ Sci Technol 2009, 43, (17), 6488-92.

60. Streets, D. G.; Yarber, K. F.; Woo, J. H.; Carmichael, G. R., Biomass burning in Asia: Annual and seasonal estimates and atmospheric emissions. Global Biogeochemical Cycles 2003, 17, (4).

61. Liu, D.; Lin, T.; Syed, J. H.; Cheng, Z.; Xu, Y.; Li, K.; Zhang, G.; Li, J., Concentration, source identification, and exposure risk assessment of PM2.5-bound parent PAHs and nitro-PAHs in atmosphere from typical Chinese cities. Scientific Reports 2017, 7, (1), 10398.

62. Hu, D.; Hornbuckle, K. C., Inadvertent Polychlorinated Biphenyls in Commercial Paint Pigments. Environmental Science \& Technology 2010, 44, (8), 2822-2827.

63. Weizhe, H.; Yingming, L.; Linnan, Z.; Jia, B.; Pu, W.; Chaofei, Z.; Qinghua, Z., Levels and distribution of polychlorinated biphenyls in the atmosphere of Beijing. Environmental Chemistry (in Chinese) 2015, 34, (3), 410-416.

64. Chinese Dyestuff Industry-present situation and development (in Chinese); CDIA: 2018.

65. Rauert, C.; Harner, T.; Schuster, J. K.; Eng, A.; Fillmann, G.; Castillo, L. E.; Fentanes, O.; Villa Ibarra, M.; Miglioranza, K. S. B.; Moreno Rivadeneira, I.; Pozo, K.; Aristizábal Zuluaga, B. H., Atmospheric Concentrations of New Persistent Organic Pollutants and Emerging Chemicals of Concern in the Group of Latin America and Caribbean (GRULAC) Region. Environmental Science \& Technology 2018, 52, (13), 7240-7249.

66. Grosso, M.; Biganzoli, L.; Rigamonti, L.; Cernuschi, S.; Giugliano, M.; Poluzzi, V.; Biancolini, V., Experimental evaluation of PCDD/Fs and PCBs release and mass balance of a WTE plant. Chemosphere 2012, 86, (3), 293-299.

67. Van Caneghem, J.; Block, C.; Van Brecht, A.; Wauters, G.; Vandecasteele, C., Mass balance for POPs in hazardous and municipal solid waste incinerators. Chemosphere 2010, 78, (6), 701708. 